\title{
Historical Prostate Cancer Screening and Treatment Outcomes from a Single Institution
}

\author{
Deanna S. Cross, PhD; Mark Ritter, MD, PhD; and Douglas J. Reding, MD, MPH, FACP
}

Objective: To quantify outcomes of individuals diagnosed and treated for prostate cancer in a single institution.

Design: Retrospective electronic chart abstraction.

Setting: Marshfield Clinic, the largest private multispecialty group practice in Wisconsin, and one of the largest in the United States, provides health care services annually to approximately 385,000 unique patients through I.8 million annual patient encounters.

Participants: Individuals within the Marshfield Clinic cancer registry who had been diagnosed with prostate cancer between 1960 and 2009.

Methods: Electronic chart abstraction from the cancer registry and the electronic medical record was conducted $(\mathrm{N}=6,18 \mathrm{I})$. Data abstracted included age at diagnosis; stage and grade of tumor; prostate specific antigen (PSA) values before, at, and after diagnosis; initial cancer treatment; follow-up time; subsequent cancer treatments; evidence of metastasis; age of death; and cause of death, if known.

Results: The average age of prostate cancer diagnosis has decreased from 70-7I years in the 1960's and 1970's to an average age at diagnosis of 67 years in the 2000's $(P<0.00 \mathrm{I})$. This decrease in age occurred within the decades of implementation of PSA screening. Approximately $74 \%$ of men diagnosed with prostate cancer within the PSA screening era had at least one PSA test, and the presence of a PSA test did not appear to change treatment outcome. Age, grade, and stage were the biggest predictors of prostate cancer outcome. There was no difference in event-free survival between current treatment types (radical prostatectomy, brachytherapy, photon treatment, or intensity-modulated radiation therapy) (2003 or later) when stratified by age (greater than $85 \%$, 5 -year event-free survival $P=0.85$ ); however, more events occurred with older external beam radiation treatment regimens (1993-2003) ( $70 \%$ to $75 \%, 5$-year event-free survival $P=0.00 \mathrm{I})$.

Conclusion: Individuals diagnosed and treated for prostate cancer within the Marshfield Clinic comprehensive care setting follow national trends with a decreased age of diagnosis since the advent of PSA screening. Outcomes for individuals treated within the Clinic system are also comparable to national trends.

Keywords: PSA testing; Prostate cancer; Treatment; Outcomes

\footnotetext{
Corresponding Author: Deanna S. Cross, PhD; Center for Human 
$\mathrm{D}$

espite the prevalence of prostate cancer (it is the most frequently diagnosed cancer in males over the age of 50), ${ }^{1}$ a number of uncertainties regarding the use of screening tests and treatment regimens exist. This has become more evident with the recent focus on comparative effectiveness research, where at least three questions regarding the efficacy of current prostate cancer care practices were ranked within the top 50 health care priorities for research. ${ }^{2}$ Until the completion of randomized controlled trials to answer these pressing questions, we can characterize the historical treatment and screening trends.

With the development of the prostate specific antigen (PSA) test in the late 1980's, prostate cancer incidence increased dramatically; yet, questions have remained regarding the ability of the test to distinguish clinically relevant disease from indolent disease, ${ }^{3-6}$ and also whether the test truly saves lives through early detection. ${ }^{3-6}$ There are a number of recommendations regarding screening, including age-specific PSA values ${ }^{7}$ and characterizing the population into groups to increase the benefit of screening. ${ }^{8}$ Recently, there was a proposal to stratify the population based on genetic background with different PSA cutoff values for biopsy for each group. ${ }^{9}$ The US Preventative Services Task Force most recent draft recommendation, which is still undergoing comment, recommends against any PSA screening for prostate cancer in non-symptomatic males. ${ }^{10,11}$

Long-term studies designed to answer questions regarding screening, such as the Prostate, Lung, Colorectal and Ovarian (PLCO) Cancer Screening trial in the United States and the European Randomized Study of Screening for Prostate Cancer (ERSPC) trial in Europe, are still ongoing, and in the interim have reported conflicting results regarding the benefit of screening. ${ }^{12-14}$ Despite these ongoing questions, screening is widespread in the US population, ${ }^{15,16}$ with over $50 \%$ of the participants in the PLCO control arm undergoing PSA screening. ${ }^{12}$ Here we report characteristics of prostate cancers diagnosed with and without PSA testing.
Once prostate cancer is diagnosed, there are a number of treatments for clinically localized prostate cancer. Patients and providers can choose watchful waiting, active surveillance, radiation therapy, or radical prostatectomy. To add to the number of possible choices, newer treatments such as robotic assisted surgery, internal brachytherapy, intensity modulated external beam radiation therapy, and the combined use of hormonal agents with radiation have all become available for the treatment of prostate cancer. ${ }^{17-19}$ Even as the number of treatment options continues to expand, systematic reviews of treatment options have failed to determine a clear advantage of any single treatment. ${ }^{19}$ Patients and providers are faced with a lack of clear guidelines regarding which treatment option offers the best long-term disease-free or survival benefit, and they often choose treatments based on potential side effects. ${ }^{20,21}$ Even when long-term information is available, standard radiation dosage and delivery systems have evolved over the past 10 years, making comparisons even more difficult. ${ }^{22,23}$ The need to address the lack of clear comparative effectiveness trials has been placed in the top tier of the research priorities set by the federal government. ${ }^{2}$

Here, we describe the historical outcomes of a populationbased cohort of patients diagnosed with prostate cancer at a single multi-specialty institution in rural Wisconsin. Using the electronic medical record (EMR) and a cancer registry that has recorded outcomes from 1960 to the present day; we investigated prostate cancer outcomes in both the pre- and post-PSA era. This rich historical dataset provides an opportunity to describe the outcomes from all treatment options offered by the institution.

\section{Materials and Methods \\ Population}

This study was conducted using the population from the Marshfield Clinic in Marshfield, Wisconsin. Marshfield Clinic is the largest, private, multispecialty, group practice in Wisconsin and one of the largest in the United States, providing health care services annually to approximately 385,000 unique patients through 1.8 million annual patient

Table 1. Summary of the phenotypic data collected electronically from patient medical records.

\begin{tabular}{lll}
\hline Data Element Collected & Type of Data & Associated values \\
\hline PSA values & Laboratory values & Time (pre- or post-diagnosis) \\
Age at diagnosis & In years & \\
Clinical grade and stage & Gleason grade & TNM staging \\
& Gleason grade & Age \\
Pathological grade and stage & TNM staging & Site of metastasis \\
Treatment & Radiation/Surgery/Hormone & Cause of death \\
Recurrence & Yes/No/Unknown & Yes/No/Unknown \\
Metastasis & Alive/Dead & In years \\
Vital status & Age at last follow-up
\end{tabular}

PSA, prostate specific antigen; TNM, tumor, node, metastasis 
encounters. Marshfield Clinic serves the populations of north-central and western Wisconsin and the Upper Peninsula of Michigan, with a central Marshfield campus and 43 regional clinics. Marshfield Clinic works closely with St. Joseph's Hospital in Marshfield (a 524 bed acute-care facility) to provide primary, secondary, and tertiary care for individuals regardless of financial status. Marshfield Clinic maintains a joint EMR system with St. Joseph's Hospital, including computerized diagnostic files dating back to 1963 . Within the area surveyed for this study, approximately $90 \%$ of the population receives their entire health care from Marshfield Clinic and St. Joseph's Hospital. While race and ethnicity were not explicitly requested for this study, we expect minority enrollment to reflect the population of Wisconsin, with approximately $97 \%$ of the cohort being Caucasian. This study was approved by the Marshfield Clinic Institutional Review Board.

\section{Electronic Chart Abstraction}

Electronic chart abstractions were performed from the EMRs of adult males with a diagnosis of prostate cancer. The Marshfield Clinic, Clinical and Administrative (transaction) Processing System (MARS) supplies a fully featured EMR, with an electronic data warehouse that captures the detail of visits, providers, diagnoses, procedures, and vitals, and includes a sophisticated laboratory management system that electronically records all patient laboratory tests and test results. These are coupled with clinical registries that contain data that is either collected at the time of patient care or retrospectively collected by abstracting the EMR. The majority of the clinical registry systems collect data for the purpose of evaluating patient outcomes, benchmarking, accreditation, or management reporting. For each individual diagnosed with prostate cancer, we collected screening and treatment information from the available databases (table 1).

\section{Data Analysis}

Prostate cancer diagnostic and treatment trends over the course of four decades were described. Summary statistics for each variable were stratified by decade, missing information, and treatment trends were highlighted.

\section{PSA Screening}

To investigate PSA screening patterns in the diagnosis of prostate cancer, the number of PSA-screened cancers diagnosed was determined in 2-year increments, as well as the average PSA value at diagnosis. We stratified the PSAscreened prostate cancers by the age of diagnosis to determine age trends. For these analyses, we used individuals diagnosed with prostate cancer from 1990 to 2008 to capture historic trends in PSA-screened cancers. Summary statistics and univariate chi-squared analysis for stage, grade, and age at diagnosis were also performed for individuals with PSAscreened prostate cancers and those with prostate cancer not diagnosed via PSA screening.

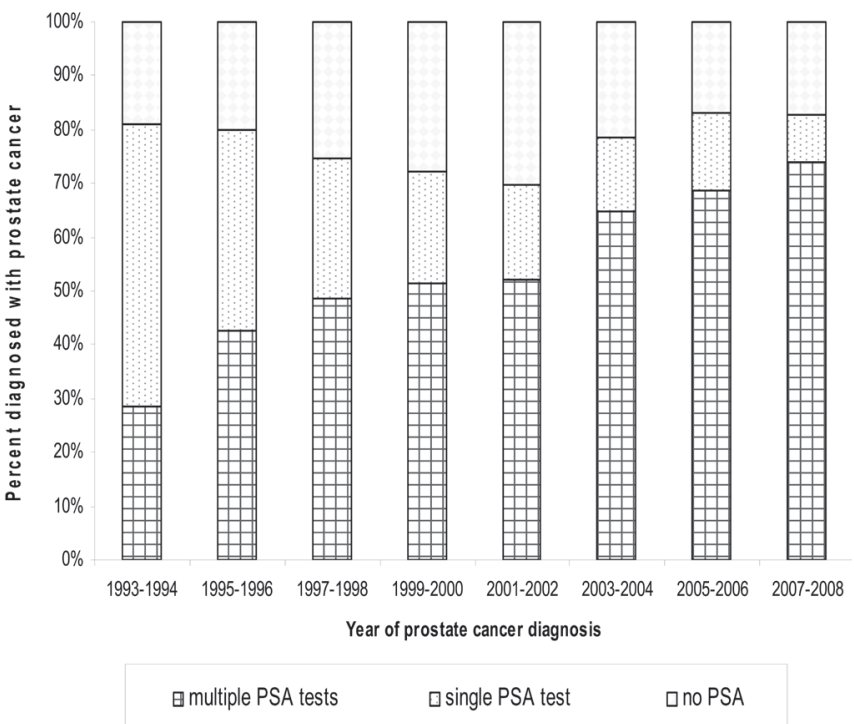

Figure 1: PSA screening trends over time (1993-2008) $(n=3288)$ as a percentage of individuals diagnosed with prostate cancer with zero, one, or multiple recorded PSA tests.

\section{Treatment Outcomes}

We summarized treatment trends in 3-year increments based on age at diagnosis, PSA screening, and tumor stage. We also summarized recurrence based on treatment type for each age group and stage. In our treatment data, external beam radiation therapy (EBRT) was characterized into two different treatment types; EBRT of an undefined dosage and photon treatment with a specified dosage. Because the EBRT category represented an earlier radiation treatment, we chose to keep these categories separate for analysis. Finally, we summarized average number of years between treatment and biochemical recurrence, death, or metastasis. Prostate cancer death was recorded from the cancer registry cause of death field, and was only counted in the total death count if prostate cancer was listed as the cause of death. Recurrence and metastasis required a physician to document this in the medical record for incorporation into the cancer registry file. Recurrence based on PSA values would differ dependent on treatment type; as an example, for radical prostatectomy this would mean a rising PSA beyond $0.02 \mathrm{ng} / \mathrm{mL}$, and for radiation therapy 2x PSA nadir. All summary and univariate chi-squared analyses were performed using SAS v9.1 (SAS Institute, Cary, North Carolina).

\section{Results}

\section{Patient Characteristics by Decade}

For each decade, the average age at diagnosis, tumor grade, average number of years of follow-up available, number of known deaths from all-cause mortality, and the average number of prostate-specific deaths were recorded $(\mathrm{N}=6181)$ (table 2). While the number of individuals diagnosed with prostate cancer was available from 1960 to the present, PSA values were only available since the introduction of the 
Table 2. Summary of patient characteristics for prostate cancer diagnoses at the Marshfield Clinic by decade ( $\mathrm{N}=6181)$.

\begin{tabular}{llllll}
\hline Decade & $\mathbf{1 9 6 0}$ 's & $\mathbf{1 9 7 0}$ 's & $\mathbf{1 9 8 0}$ 's & $\mathbf{1 9 9 0}$ 's & 2000's \\
\hline Diagnosed (n) & 361 & 764 & 1107 & 2021 & 1928 \\
Age at diagnosis (Avg) & 71.5 & 71.0 & 72.2 & 70.4 & 67.2 \\
Grade (Median) & - & - & - & 2 & 2 \\
Stage (Median) & - & - & - & 2 & 2 \\
Years of follow up (Avg) & 6.1 & 7.5 & 8.3 & 9.1 & 3.5 \\
Known death -all cause & 83 & 502 & 1107 & 1163 & 291 \\
(Avg. age) & $(80.3)$ & $(79.6)$ & $(80.4)$ & $(80.6)$ & $(76.4)$ \\
$\begin{array}{l}\text { Death - Prostate specific } \\
\text { (Avg age) }\end{array}$ & 8 & 126 & 298 & 224 & 56 \\
Recurrence (n) & $(81.4)$ & $(77.2)$ & $(76.9)$ & $(78.5)$ & $(75.4)$ \\
Metastasis (n) & 1 & 47 & 143 & 393 & 78 \\
\# With at least one PSA & 0 & 148 & 188 & 110 & 75 \\
(before diagnosis) & 41 & 0 & 3 & 1493 & 1516 \\
\# PSA tests pre-diagnosis (Avg) & 0 & 0 & 0 & 1.4 & 5.75 \\
\hline
\end{tabular}

PSA, prostate specific antigen.

clinical test (1990), and Gleason grading was available beginning in 1992. The TNM (tumor, node, metastasis) staging was available from 1990 and before 1997; if both clinical and pathological stage were collected, only one was kept by the cancer registry.

Despite the limitations of the data, we were able to discern clear trends in diagnosis and treatment over time. The average age of diagnosis decreased with the advent of the PSA test, with an average age in the early 70's (years) in the decades before PSA, decreasing to age 67 years in the current decade (table 2). PSA testing was prevalent in our population, with approximately $74 \%$ receiving at least one PSA test at or before prostate cancer diagnosis in the decade of the 1990's and an even greater percentage receiving at least one PSA test in the current decade (table 2).

\section{Outcome With and Without PSA Testing}

We stratified the population into individuals who had more than one PSA test at cancer diagnosis, those with exactly one PSA test prior to diagnosis, and those with no PSA test prior to diagnosis for those years following the implementation of PSA testing from 1993 to $2008(n=3288)$. For these years, $70 \%$ or more of our population had at least one PSA test, with the percentage of individuals with only one PSA test at diagnosis decreasing from $52.39 \%$ in $1993-1994$ to $8.96 \%$ in 2007-2008 (figure 1). Because of the observed decrease in the age at diagnosis with the advent of PSA testing, we stratified the population diagnosed from 2002 through 2008 $(\mathrm{n}=1302)$ by PSA test and age of diagnosis (figure 2$)$. Interestingly, those diagnosed at a younger age $(\leq 63)$ were the group most likely to be diagnosed without a PSA test (approximately 20\%) and with only one PSA test (approximately 15\%).

Using this same population (those diagnosed from 2002 through 2008, $\mathrm{n}=1238$ ), we stratified PSA testing into localized (stage 1 or $2, \mathrm{n}=1042$ ) or advanced (stage 3 or 4 , $\mathrm{n}=214$ ) disease, excluding those without a known stage $(\mathrm{n}=63)$. Individuals without a PSA test or with only a single PSA test were more likely to be diagnosed with advanced disease ( $P=0.0001), 15 \%$ with multiple PSA tests versus $30 \%$ with a single PSA test, and $20 \%$ with no PSA testing (figure

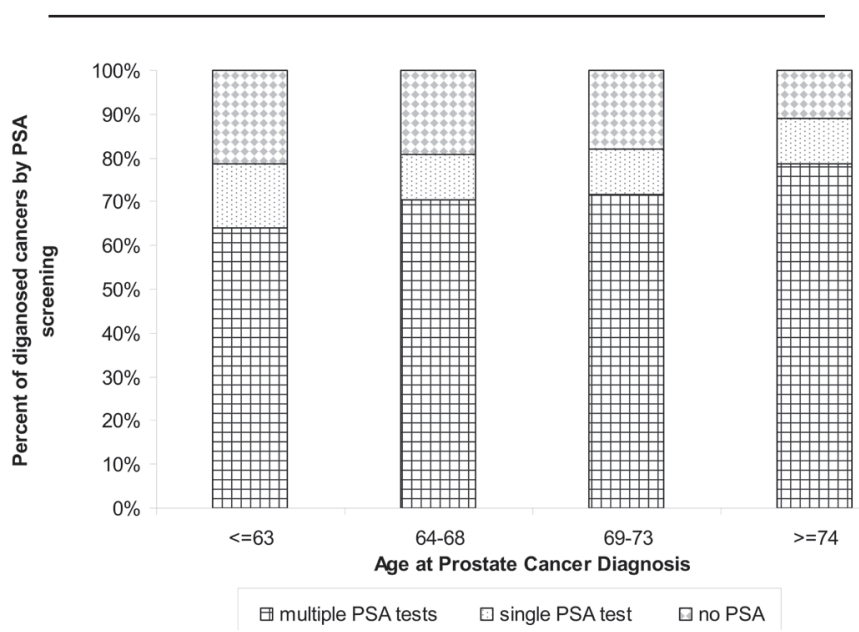

Figure 2: Prostate cancer diagnosis with and without PSA screening (2002-2008) stratified by age at diagnosis $(n=1302)$. 


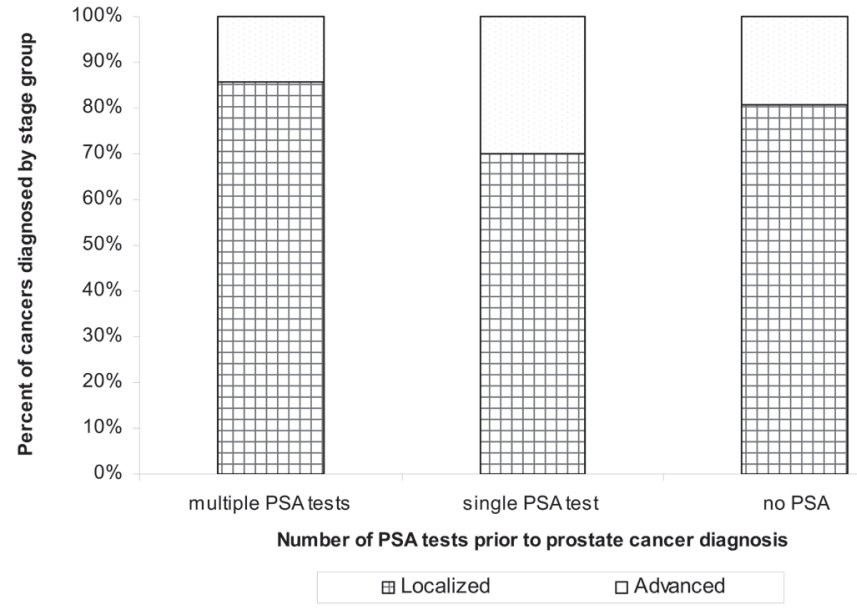

Figure 3: Percent of advanced stage prostate cancers stratified by recorded PSA tests before diagnosis $(n=1238)$.

3). We were unable to discern differences in prostate-specific mortality in the screened versus unscreened population because of the limited number of documented prostate cancer deaths in this population $(\mathrm{n}=20)$, and the fact that most of these deaths occurred in the indeterminate group, a single PSA screen at diagnosis $(\mathrm{n}=11)$.

\section{Treatment Characteristics by Decade}

Patient characteristics for treatment, including the number and average age at treatment, were captured for each decade. The first course of each treatment was captured for each patient. However, due to the nature of the data reported here (by year), we are unable to determine which treatment was the initial treatment when all treatments were in the same year.

The age of first treatment course has decreased by up to a decade, particularly for surgery, with the age decreasing from approximately 72 years in the early decades to approximately 63 years currently. To further determine the most recent

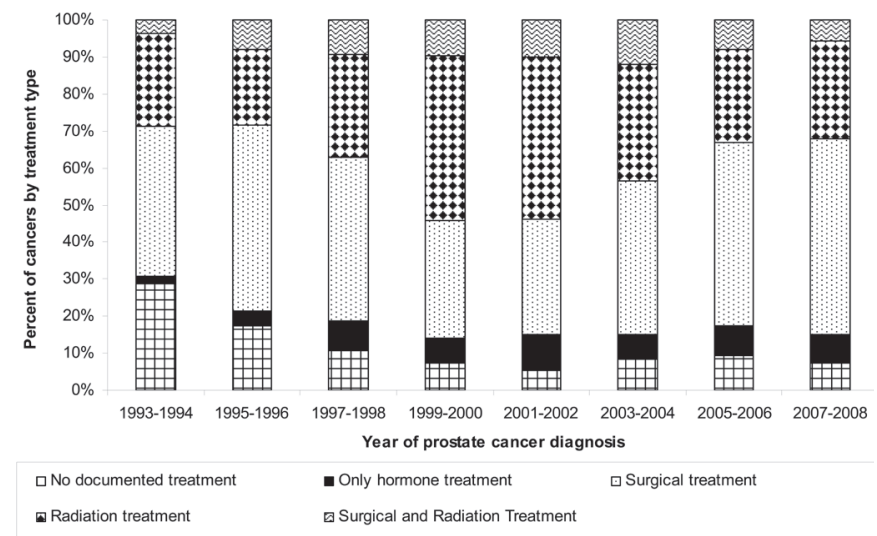

Figure 4: Treatment trends for prostate cancer over time (1993-2008) as a percentage of individuals diagnosed with cancer $(n=3288)$. treatment trends, we stratified treatment from 1993 through $2008(n=3288)$ into five categories: no treatment, treatment with hormone only, surgical treatment, radiation treatment, and both radiation and surgical treatment. The proportion of individuals receiving surgery as a first treatment course increased from approximately $40 \%$ in $1993-1994$ to $53 \%$ in 2007-2008 (figure 4). Interestingly, radiation treatment as a first course has not exhibited a consistent pattern, with increases in the percent treated in 1999-2002, but with the percent treated decreasing after 2002. The type of treatment was associated with age at diagnosis $(P=0.0001)$, with individuals diagnosed at a younger age more likely to receive surgical interventions $(62 \%$ for individuals 63 years or younger versus $21 \%$ of those diagnosed over the age of 74 ) (figure 5). Individuals over the age of 74 were most likely to receive conservative treatments such as no treatment or hormonal-only treatment $(46 \%$ with these two combined treatments versus $5 \%$ for the youngest age group) (figure 5).

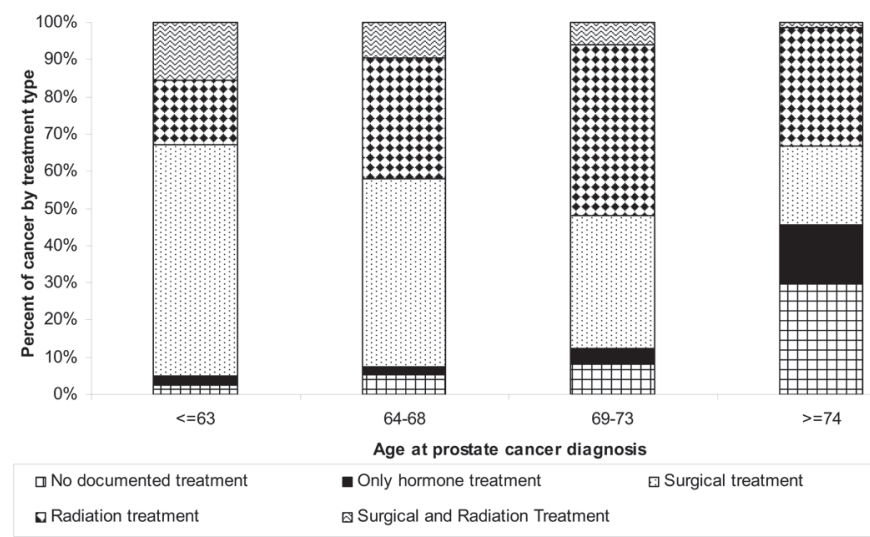

Figure 5: Prostate cancer treatment trends by age group, as a percentage of individuals diagnosed with cancer $(n=3288)$.

\section{Treatment Outcomes}

We further characterized treatment in the modern era by determining the recurrence, metastasis, and documented prostate cancer deaths in a subset of our population. Individuals with localized disease (stage 1 or 2) who were treated with radical prostatectomy, brachytherapy, EBRT, or combination therapy were included in the population ( $\mathrm{n}=1895)$. Individuals with indeterminate treatment such as unspecified radiation or surgery or no documented treatment were excluded from the population. Using this criteria, there were 21 recorded prostate cancer specific deaths. We then characterized treatment with regard to recurrence and metastasis documentation in the cancer registry, based on abstraction from the medical record. Total event-free survival was tabulated across all events (recurrence, metastasis, and death), and an individual with multiple events was only counted once. As anticipated, the percentage of events increased from $2 \%$ for those treated in 2007-2008 with an average of 1-year of follow-up time, to $26 \%$ for those treated in 1993-194 with up to 15 years of follow-up information available. 


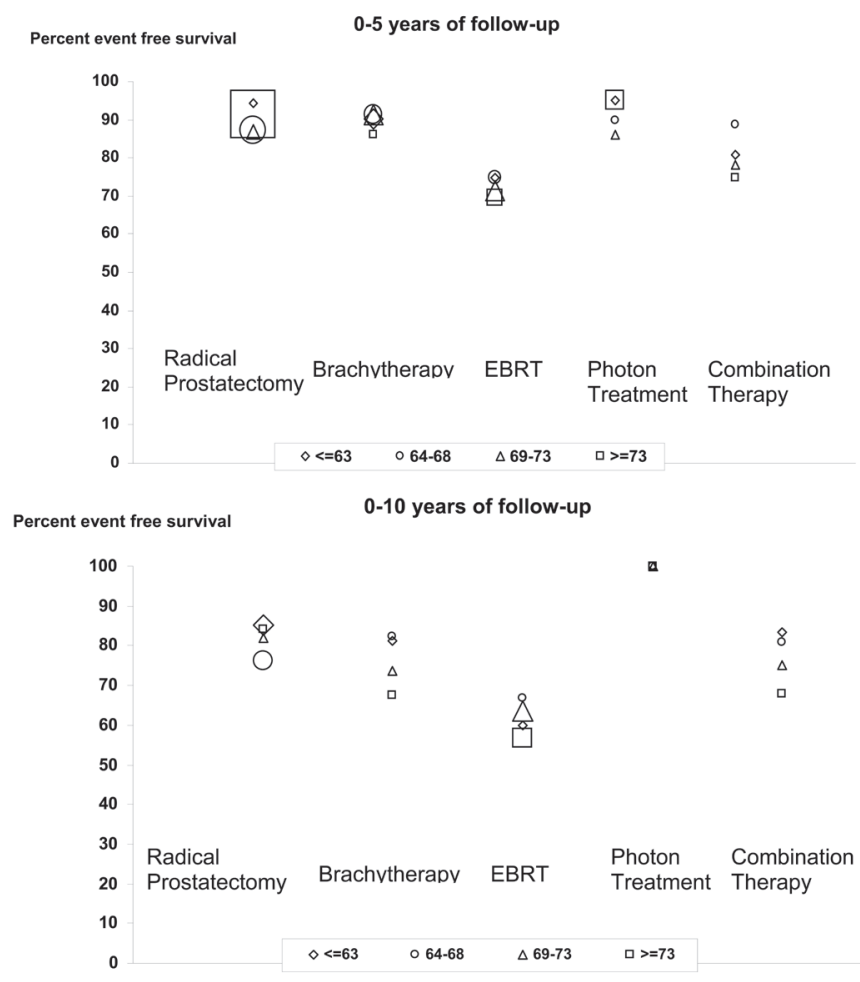

Figure 6: Event free survival for prostate cancer treatment by treatment type and age group for 5 and 10 year survival $(n=1857)$. The number of individuals in each age and treatment group is represented by the size of the symbol ( $\square \leq 75, \square \leq 150, \square \leq 300, \square \geq 500$ ).

To better characterize event-free survival, we stratified treatments by age group, treatment type, and number of years of follow-up information ( $0-5$ years, $0-10$ years, and $10+$ years) (figure 6). The oldest radiation treatment, EBRT with an unspecified dose, compared poorly with all other treatments $(P \leq 0.001), 73 \%$ average 5-year event-free survival, and a $62 \% 10$-year event-free survival, versus $90 \%$ average 5 -year event-free survival and a $76 \%$ or greater 10 -year event-free survival for other treatments (figure 6). Differences between treatments such as brachytherapy, intensity modulated radiation therapy, photon treatment of specified dosage, and radical prostatectomy were not significantly different $(P=0.85)$. Few comparisons can be made due to the small number of individuals with over 10 years of treatment history, but the trend toward prostatectomy and brachytherapy outperforming older EBRT treatments is still seen.

\section{Discussion}

Here we investigate the historical screening and treatment outcomes of a single institution. Our use of the EMR for determination of both historic and current prostate cancer treatment outcomes provided evaluable, useful data, even when derived from patients treated decades ago. On average, we had over 8 years of recorded follow-up on individuals treated beginning in 1980. We were able to demonstrate changing PSA screening trends and a decreased age at initial diagnosis. In addition, we could highlight the changing treatment patterns with age of diagnosis. Using all available outcome fields from the cancer registry (metastasis, recurrence, and death), we were able to categorize outcomes for both current treatments and historic treatments for both surgical and radiation patients.

However, the electronic records did have several limitations. PSA testing could not be unequivocally considered screening without further manual chart review. Other factors that affect PSA screening such as insurance status and socioeconomic status were not considered in this study. We did not capture the frequency of healthcare visits; therefore, it is difficult to determine whether the lack of a PSA test was due to intentionally declined screening or lack of access to a healthcare provider. We also did not capture digital rectal examinations. We were unable to easily capture the Gleason score for our prostate cancer patients, as this information is not routinely kept in our cancer registry. We could not capture the intent to treat, particularly when no treatment was performed; therefore, we make no comparisons between treatment and watchful waiting or active surveillance. We captured the type of radiation treatment within our cancer registry, but the radiation dosage is not stored in a field available for electronic queries, making comparisons difficult. EBRT is split in our cancer registry into photon treatment with dosage and EBRT without a dosage, which is a proxy for the older radiation treatment regimen. Another limitation of this study is its observational retrospective nature.

Despite these limitations, this study can provide insight into both national and institutional practice trends. Historic information for age at first prostate cancer diagnosis and treatment type follows national trends. Using the National Cancer Institute's (NCI) Surveillance Epidemiology and End Results (SEER) database, Lin et $\mathrm{al}^{24}$ found the average age of diagnosis decreased from 72 years in 1988 to 68 years by 2003; and Bock et $\mathrm{a}^{25}$ recorded a trend toward decreasing age at diagnosis in successive generations in families with a history of prostate cancer. Our data mirrored this trend, with the first diagnosis of prostate cancer decreasing from age 72 in the decade prior to PSA testing to age 67 in the current decade (2000's). While we did not have enough historical stage and grade information to discern if there has been a trend toward less aggressive cancer, nationally this trend has been observed..$^{26,27}$ Our data did indicate that those diagnosed without a prior PSA screening were more likely to have advanced disease stage, $\mathrm{T} 2 \mathrm{c}$ or greater.

The individuals diagnosed without a prior PSA screening or with only a single PSA test were more likely to have advanced cancer. This most likely represents a group of patients with symptomatic cancer, or digital rectal exam screened patients; but, we did not pursue further chart review to investigate these possibilities. However, this is consistent with other studies that have compared individuals who are diagnosed with and without PSA testing. In the large US screening trial, PLCO, individuals who were diagnosed with prostate cancer 
based on symptoms or a digital rectal exam were more likely to be diagnosed with advanced prostate cancer. ${ }^{28}$ When Pelzer et $\mathrm{al}^{29}$ compared PSA screened patients to patients referred without PSA screening, those with no screening were more likely to have higher grade and stage cancer.

For the second group of patients most likely to be diagnosed with advanced cancer, those with only a single PSA test, we did not determine if the single PSA test was a diagnosis at first screen or whether the suspicion of cancer or cancer symptoms initiated a PSA test. Further chart review would be necessary in the future. It is not surprising that initial PSA testing produced a large number of positive cancers. The PLCO outcomes indicated a larger positive predictive value for the first PSA screening, ${ }^{28}$ and the ERSPC trial also found that cancers detected with the initial screening were more likely to be advanced stage. ${ }^{30}$ This may explain the larger number of individuals diagnosed with prostate cancer with a first screen in the younger age groups.

Prostate cancer therapy trends at our institution closely mirrored others reported, with radical prostatectomy treatment approaching 49\%, radiation therapy (both external and brachytherapy combined) $25 \%$, no treatment approaching $9 \%$, and hormonal therapy of approximately $8 \%$ at our institution. This is similar to the trends reported by NCI SEER outcomes (45\% radical prostatectomy, $24 \%$ total radiation, $8 \%$ hormonal, and $9 \%$ watchful waiting $)^{31}$ and within the regional trends reported by the Centers for Disease Control and Prevention (CDC) National Program of Cancer Registries (NPCR) Patterns of Care (PoC1) study. ${ }^{32}$ Once prostate cancer was detected, we also observed a decrease in the age of surgery with successive decades, with the average age of surgical intervention as early as 63 years for the current decade and more conservative treatment likely for older age at cancer diagnosis. This trend has been observed elsewhere around the United States. Using the NCI SEER database, Lin et al noted that younger men were more likely to be treated with prostatectomy. ${ }^{24,27,33}$ The PoC1 study also found that age at diagnosis affected the likely treatment choice, with older patients more likely to receive conservative treatment and younger individuals more likely to receive radical prostatectomies. ${ }^{32}$ Single institution treatment trends, such as at Yale University, also reported a disparity in the ages of individuals receiving radical prostatectomy versus radiation implant treatment, with younger individuals receiving prostatectomy. ${ }^{34}$

Comparing radical prostatectomy and radiation treatment outcomes was challenging, as we had few documented prostate cancer deaths in our population. This is one of the challenges for determining treatment outcomes in prostate cancer, with low recurrence rates and a high competing mortality rate based on the age of diagnosis of many individuals.

When using recurrence documented in the cancer registry as an endpoint, our results were similar to other institutions. It should be noted that recurrence in our study required a notation in the medical record and is based on different criteria depending on the treatment regime. Kupelian et $\mathrm{al}^{35}$ found brachytherapy and radical prostatectomy had similar biochemical failure rates and worse outcomes for low-dose EBRT. We found worse outcomes for our EBRT group when compared to brachytherapy and radical prostatectomy as well; but, we were unable to separate low- and high-dose EBRT, since we did not have dose information. A study of radioactive implant versus surgery found no differences in survival when comparing treatment at Yale University School of Medicine from 1992 through 2005. ${ }^{34}$ Our data contrasts with the Swiss study that concluded that surgical treatment had the best long-term survival rates for younger patients, ${ }^{36,37}$ however, this study did not specify radiation dosages, used clinical grading and staging for radiation patients, and pathological grading and staging for surgery patients, all of which may account for some of the survival differences. ${ }^{22}$ It should be encouraging to patients and providers that currently we do not see clear treatment benefits from a particular type of treatment, and any treatment received appears to have a beneficial 5- and 10-year event-free survival horizon.

\section{Conclusions}

In this study, we used entirely electronic data collection to determine the historical trends for treatment and outcomes for the Marshfield Clinic. The prostate cancer screening and treatment trends for the Marshfield Clinic have followed national patterns. Prostate cancer detected from screening was less likely to be advanced stage. In this study, age at diagnosis influenced treatment trends.

\section{Acknowledgements}

Cancer Research Network (CRN) grant title: Cancer Research Network Across Health Care Systems, Grant \#: U19 CA 79689. The HMO Research Network, of which the CRN is a part, consists of the research programs, enrollee populations and databases of 14 HMO members of the HMO Research Network. The overall goal of the CRN is to conduct collaborative research to determine the effectiveness of preventative, curative, and supportive interventions for major cancers that span the natural history of those cancers among diverse populations and health care systems. The 14 health plans, with nearly 11 million enrollees are distinguished by their longstanding commitment to prevention and research, and collaboration among themselves and with affiliated academic institutions.

NCRR/NIH Institutional Clinical and Translational Science Award grant title: NCRR/NIH Institutional Clinical and Translational Science Award (UW-Madison) (KL2-Awardee), Grant\#: 1UL1RR025011. The goal of the UW-ICTR is to create an environment that facilitates the transformation of research at the University into a continuum extending from investigation through discovery to translation into practice.

Project Title: Development of an individualized risk assessment for secondary complications of radiation therapy for prostate cancer. Role: ICTR KL2 Scholar 
We would like to thank the Marshfield Clinic Research Foundation Biomedical Informatics Research Center for data collection.

\section{References}

1. Edwards BK, Ward E, Kohler BA, Eheman C, Zauber AG, Anderson RN, Jemal A, Schymura MJ, Lansdorp-Vogelaar I, Seeff LC, van Ballegooijen M, Goede SL, Ries LA. Annual report to the nation on the status of cancer, 1975-2006, featuring colorectal cancer trends and impact of interventions (risk factors, screening, and treatment) to reduce future rates. Cancer 2010; 16:544-573.

2. Committee on Comparative Effectiveness Research Prioritization. Institute of medicine, initial national priorities for comparative effectiveness research. Washington, D.C.: National Academies Press; 2009.

3. Penson DF, Rossignol M, Sartor AO, Scardino PT, Abenhaim LL. Prostate cancer: epidemiology and health-related quality of life. Urology 2008; 72:S3-S11.

4. van Leeuwen PJ, Connolly D, Gavin A, Roobol MJ, Black A, Bangma CH, Schröder FH. Prostate cancer mortality in screen and clinically detected prostate cancer: Estimating the screening benefit. Eur J Cancer. 2010; 46:377-383.

5. Welch HG, Albertsen PC. Prostate cancer diagnosis and treatment after the introduction of prostate-specific antigen screening: 1986-2005. J Natl Cancer Inst 2009; 101:1325-1329.

6. Lu-Yao G, Albertsen PC, Stanford JL, Stukel TA, WalkerCorkery E, Barry MJ. Screening, treatment, and prostate cancer mortality in the Seattle area and Connecticut: fifteen-year follow-up. J Gen Intern Med 2008; 23:1809-1814.

7. Veltri RW, Miller MC, O'dowd GJ, Partin AW. Impact of age on total and complexed prostate-specific antigen cutoffs in a contemporary referral series of men with prostate cancer. Urology 2002; 60:47-52.

8. Greene KL, Albertsen PC, Babaian RJ, Carter HB, Gann PH, Han M, Kuban DA, Sartor AO, Stanford JL, Zietman A, Carroll P. Prostate specific antigen best practice statement: 2009 update. J Urol 2009; 182:2232-2241.

9. Witte JS. Personalized prostate cancer screening: improving PSA tests with genomic information. Sci Transl Med 2010; 2:62ps55.

10. US Preventative Services Task Force. Screening for prostate cancer. Available at http://www. uspreventiveservicestaskforce.org/uspstf/uspsprca.htm. Accessed June 11, 2012.

11. Chou R, Croswell JM, Dana T, Bougatsos C, Blazina I, Fu R, Gleitsmann K, Koenig HC, Lam C, Maltz A, Rugge JB, Lin $\mathrm{K}$. Screening for prostate cancer: a review of the evidence for the U.S. Preventive Services Task Force. Ann Intern Med 2011; 155:762-771.

12. Barry MJ. Screening for prostate cancer--the controversy that refuses to die. N Engl J Med 2009; 360:1351-1354.

13. Schröder FH, Hugosson J, Roobol MJ, Tammela TL, Ciatto S, Nelen V, Kwiatkowski M, Lujan M, Lilja H, Zappa M, Denis LJ, Recker F, Berenguer A, Määttänen L, Bangma CH, Aus G, Villers A, Rebillard X, van der Kwast T, Blijenberg BG, Moss SM, de Koning HJ, Auvinen A; ERSPC Investigators. Screening and prostate-cancer mortality in a randomized European study. N Engl J Med 2009; 360:1320-1328.
14. Andriole GL, Crawford ED, Grubb RL 3rd, Buys SS, Chia D, Church TR, Fouad MN, Gelmann EP, Kvale PA, Reding DJ, Weissfeld JL, Yokochi LA, O’Brien B, Clapp JD, Rathmell JM, Riley TL, Hayes RB, Kramer BS, Izmirlian G, Miller AB, Pinsky PF, Prorok PC, Gohagan JK, Berg CD; PLCO Project Team. Mortality results from a randomized prostatecancer screening trial. N Engl J Med 2009; 360:1310-1319. Erratum in: N Engl J Med 2009; 360:1797.

15. Farwell WR, Linder JA, Jha AK. Trends in prostate-specific antigen testing from 1995 through 2004. Arch Intern Med 2007; 167:2497-2502.

16. Ross LE, Berkowitz Z, Ekwueme DU. Use of the prostatespecific antigen test among U.S. men: findings from the 2005 National Health Interview Survey. Cancer Epidemiol Biomarkers Prev 2008; 17:636-644.

17. Jereczek-Fossa BA, Curigliano G, Orecchia R. Systemic therapies for non-metastatic prostate cancer: review of the literature. Onkologie 2009; 32:359-363.

18. Ladjevardi S, Sandblom G, Berglund A, Varenhorst E. Tumour grade, treatment, and relative survival in a population-based cohort of men with potentially curable prostate cancer. Eur Urol 2010; 57:631-638.

19. Dahm P, Yeung LL, Chang SS, Cookson MS. A critical review of clinical practice guidelines for the management of clinically localized prostate cancer. J Urol 2008; 180:451-459; discussion 460.

20. Namiki S, Arai Y. Health-related quality of life in men with localized prostate cancer. Int J Urol 2010;17:125-138

21. Gomella LG, Johannes J, Trabulsi EJ. Current prostate cancer treatments: effect on quality of life. Urology 2009; 73:S28-S35.

22. Adkison JB, Ritter MA. Prostate cancer-which treatment to choose? Arch Intern Med 2008; 168:1352; author reply 1353.

23. Biagioli MC, Hoffe SE. Emerging technologies in prostate cancer radiation therapy: improving the therapeutic window. Cancer Control 2010; 17:223-232.

24. Lin DW, Porter M, Montgomery B. Treatment and survival outcomes in young men diagnosed with prostate cancer: a population-based cohort study. Cancer 2009; 115:2863-2871.

25. Bock CH, Peyser PA, Montie JE, Cooney KA. Decreasing age at prostate cancer diagnosis over successive generations in prostate cancer families. Prostate 2005; 64:60-66.

26. Shao YH, Demissie K, Shih W, Mehta AR, Stein MN, Roberts CB, Dipaola RS, Lu-Yao GL. Contemporary risk profile of prostate cancer in the United States. J Natl Cancer Inst 2009; 101:1280-1283.

27. Pashayan N, Pharoah P, Neal DE, Hamdy F, Donovan J, Martin RM, Greenberg D, Duffy SW. Stage shift in PSA-detected prostate cancers - effect modification by Gleason score. J Med Screen 2009; 16:98-101.

28. Grubb RL 3rd, Pinsky PF, Greenlee RT, Izmirlian G, Miller AB, Hickey TP, Riley TL, Mabie JE, Levin DL, Chia D, Kramer BS, Reding DJ, Church TR, Yokochi LA, Kvale PA, Weissfeld JL, Urban DA, Buys SS, Gelmann EP, Ragard LR, Crawford ED, Prorok PC, Gohagan JK, Berg CD, Andriole GL. Prostate cancer screening in the Prostate, Lung, Colorectal and Ovarian cancer screening trial: update on findings from the initial four rounds of screening in a randomized trial. BJU Int 2008; 102:1524-1530.

29. Pelzer AE, Colleselli D, Bektic J, Schaefer G, Ongarello S, Schwentner C, Pallwein L, Mitterberger M, Steiner E, Bartsch G, Horninger W. Clinical and pathological features of screen vs non-screen-detected prostate cancers: is there a difference? BJU Int 2008; 102:24-27. 
30. Postma R, Schröder FH, van Leenders GJ, Hoedemaeker RF, Vis AN, Roobol MJ, van der Kwast TH. Cancer detection and cancer characteristics in the European Randomized Study of Screening for Prostate Cancer (ERSPC)-Section Rotterdam. A comparison of two rounds of screening. Eur Urol 2007; 52:89-97.

31. Hamilton AS, Albertsen PC, Johnson TK, Hoffman R, Morrell D, Deapen D, Penson DF. Trends in the treatment of localized prostate cancer using supplemented cancer registry data. BJU Int 2011; 107:576-584.

32. Schymura MJ, Kahn AR, German RR, Hsieh MC, Cress RD, Finch JL, Fulton JP, Shen T, Stuckart E. Factors associated with initial treatment and survival for clinically localized prostate cancer: results from the CDC-NPCR Patterns of Care Study (PoC1). BMC Cancer 2010; 10:152.

33. Hu JC, Hevelone ND, Ferreira MD, Lipsitz SR, Choueiri TK, Sanda MG, Earle CC. Patterns of care for radical prostatectomy in the United States from 2003 to 2005. J Urol 2008; 180:1969-1674.

34. Colberg JW, Decker RH, Khan AM, McKeon A, Wilson LD, Peschel RE. Surgery versus implant for early prostate cancer: results from a single institution, 1992-2005. Cancer J 2007; 13:229-232.

35. Kupelian PA, Ciezki J, Reddy CA, Klein EA, Mahadevan A . Effect of increasing radiation doses on local and distant failures in patients with localized prostate cancer. Int J Radiat Oncol Biol Phys 2008; 71:16-22.

36. Welz S, Nyazi M, Belka C, Ganswindt U. Surgery vs. radiotherapy in localized prostate cancer. Which is best? Radiat Oncol 2008; 3:23.

37. Merglen A, Schmidlin F, Fioretta G, Verkooijen HM, Rapiti E, Zanetti R, Miralbell R, Bouchardy C. Short- and long-term mortality with localized prostate cancer. Arch Intern Med. 2007; 167:1944-1950.

\section{Author Affiliations}

Deanna S. Cross, PhD*; Mark Ritter, MD, PhD广;

Douglas J. Reding, MD, MPH, FACP

*Center for Human Genetics, Marshfield Clinic Research

Foundation, Marshfield, Wisconsin

†epartment of Human Oncology, University of Wisconsin

School of Medicine and Public Health, Madison, Wisconsin

*Department of Oncology/Hematology, Marshfield Clinic,

Marshfield, Wisconsin 